\title{
Rehabilitation with Esthetic Functional Fixed Space Maintainer: A Report of Two Cases
}

\author{
Luiz ER Volpato ${ }^{1}$, Aline SB Crivelli ${ }^{2}$, Ellen TRT Oliveira ${ }^{3}$, Antonio MS Nobreza $^{4}$, Andrei Rosa $^{5}$
}

\begin{abstract}
Background: Early loss of anterior primary teeth occurs mainly due to dental caries and trauma and may cause functional changes and negatively impact children's quality of life and social interaction.

Aim and objective: This article reports two cases in which pediatric patients with different dental losses were rehabilitated with esthetic functional fixed space maintainers with tube-bar system.

Cases description: In the first case, a 3-year-old boy with a missing upper central incisor due to dental trauma was rehabilitated with an esthetic functional fixed space maintainer with tube-bar system. In the second case, a 5-year-old boy lost three upper incisors, also due to dental trauma. He was likewise rehabilitated with an esthetic functional fixed space maintainer with tube-bar system.

Conclusion: The rehabilitation of early losses of anterior primary teeth by fixed esthetic functional space maintainers with tube-bar system proved to be a favorable treatment option regardless of the age of the patient or the number of missing teeth.

Clinical significance: Early loss of anterior primary teeth may have a major impact on the pediatric patient and is still a challenge in clinical practice. This article presents an effective and inexpensive alternative to this clinical situation.

Keywords: Child, Pediatric prosthodontics, Primary dentition.

International Journal of Clinical Pediatric Dentistry (2021): 10.5005/jp-journals-10005-1921
\end{abstract}

\section{BACKGROUND}

Primary teeth have a relevant role in esthetics, phonetics, occlusion, and well-being of the child as well as in the stimulation of craniofacial growth and development, and should be maintained whenever possible. ${ }^{1,2}$ Its early loss occurs mainly due to dental caries and trauma ${ }^{3}$ and may cause functional changes in the patients as well as negatively impact on their quality of life and social interaction. ${ }^{2,4}$

Patients missing primary teeth can be rehabilitated with functional space maintainers. ${ }^{1}$ These devices can be fixed or removable and, in addition to maintaining the space for the eruption of the permanent successor tooth, they devolve the masticatory, phonetic, and esthetic functions and prevent the establishment of harmful habits, providing adequate occlusion and a good psychosocial development of the child. ${ }^{4}$

Considering the importance of rehabilitating the early loss of deciduous teeth, this article reports two cases in which pediatric patients with different dental losses were rehabilitated with esthetic functional fixed space maintainers with tube-bar system.

\section{Case Description \\ Case 1}

A 3 years and 8 months old male patient sought dental care accompanied by his mother. In the anamnesis, she reported gestation and birth without intercurrences and that the child had asthmatic bronchitis. She also reported that the boy had fallen from his own height and beaten his mouth leading to the loss of a tooth.

Physical examination revealed no extraoral abnormalities (Fig. 1). In the intraoral clinical examination, it was observed that the patient had deciduous dentition with the absence of left upper central incisor (Fig. 2).
${ }^{1}$ Department of Pediatric Dentistry, Cuiabá School of Dentistry, Universidade de Cuiabá, Mato Grosso, Brazil

${ }^{2}$ Municipality of Chupinguaia, Chupinguaia, Rondônia, Brazil

${ }^{3-5}$ Cuiabá School of Dentistry, Universidade de Cuiabá, Mato Grosso, Brazil

Corresponding Author: Luiz ER Volpato, Department of Pediatric Dentistry, Cuiabá School of Dentistry, Universidade de Cuiabá, Mato Grosso, Brazil, Phone: +556536221538, e-mail: odontologiavolpato@ uol.com.br

How to cite this article: Volpato LER, Crivelli ASB, Oliveira ETRT, et al. Rehabilitation with Esthetic Functional Fixed Space Maintainer: A Report of Two Cases. Int J Clin Pediatr Dent 2021;14(2):315-318.

Source of support: Nil

Conflict of interest: None

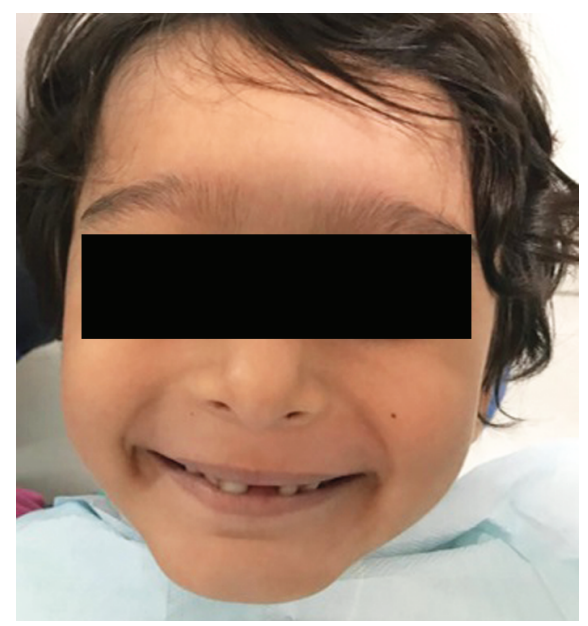

Fig. 1: Initial clinical aspect of the patient

() Jaypee Brothers Medical Publishers. 2021 Open Access This article is distributed under the terms of the Creative Commons Attribution 4.0 International License (https://creativecommons.org/licenses/by-nc/4.0/), which permits unrestricted use, distribution, and non-commercial reproduction in any medium, provided you give appropriate credit to the original author(s) and the source, provide a link to the Creative Commons license, and indicate if changes were made. The Creative Commons Public Domain Dedication waiver (http://creativecommons.org/publicdomain/zero/1.0/) applies to the data made available in this article, unless otherwise stated. 
To rehabilitate the patient, an esthetic functional fixed space maintainer with tube-bar system was proposed. Thus, orthodontic bands were adapted in the upper primary second molars. Then carried out molding with alginate.

In the following consultation, the space maintainer was tested and after the necessary adjustments were made, it was cemented with modified glass ionomer cement (RIVA, SDI, Dublin, Ireland) (Fig. 3) and a favorable esthetic was obtained (Fig. 4).

The child had good acceptance of the space maintainer and the mother reported that he showed improvement in social behavior. Currently, the child is in clinical follow-up.

\section{Case 2}

A 5-year-old male patient attended the clinic accompanied by his mother with the main complaint of absence of anterior teeth. The mother reported that the patient suffered traumatism coming to lose some teeth.

The patient showed symmetrical face with a small upper lip depression due to the absence of teeth in the region (Fig. 5). In the intraoral clinical examination, the absence of the primary upper central incisors and right lateral incisor were observed. Other changes were absent (Fig. 6).

In this case, we also opted for rehabilitation with the esthetic functional fixed space maintainer with tube-bar system. Thus,

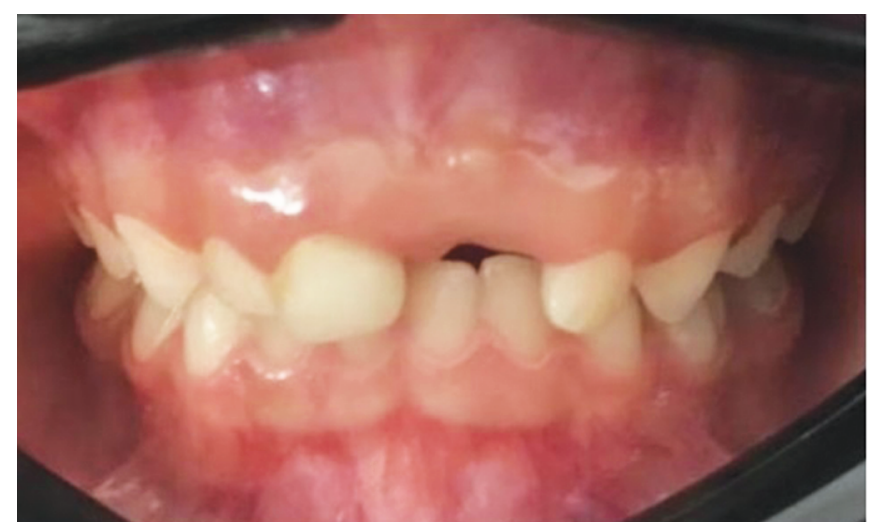

Fig. 2: Intraoral aspect of the patient showing absence of the left upper central incisor

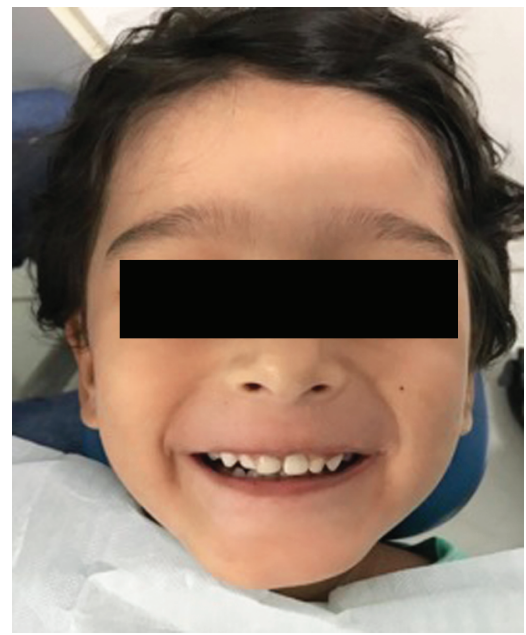

Fig. 4: Final aspect of the patient after rehabilitation with the use of esthetic functional space maintainer the next consultation followed the selection of the bands and adaptation to the second primary upper molars, molding and transferring the bands (Fig. 7).

Oral prophylaxis, proof, and cementation of the space maintainer with modified glass ionomer cement (RIVA, SDI, Dublin, Ireland) were performed at the following consultation (Figs 8 and 9).

After 210 days, the patient returned and was evaluated clinically and radiographically for prosthesis control. Good patient hygiene and no abnormalities were observed.

\section{Discussion}

The main causes of early loss of deciduous teeth are dental caries and trauma, and the upper central incisors are the more frequently affected teeth, ${ }^{1,5}$ with a preference for male sex. ${ }^{6}$ In the two reported cases, tooth loss occurred in boys, due to trauma and involving upper incisors.

Early loss of deciduous teeth may lead to decreased arch length, migration of adjacent teeth, changes in mastication, phonation, altered tongue positioning, esthetic impairment, and even emotional changes in the child. Rehabilitation with esthetic functional space maintainers is important. ${ }^{4,7}$ In the two reported cases, the main complaint of the patients and their caregivers was esthetics. However, it is worth mentioning that in case 1 the patient

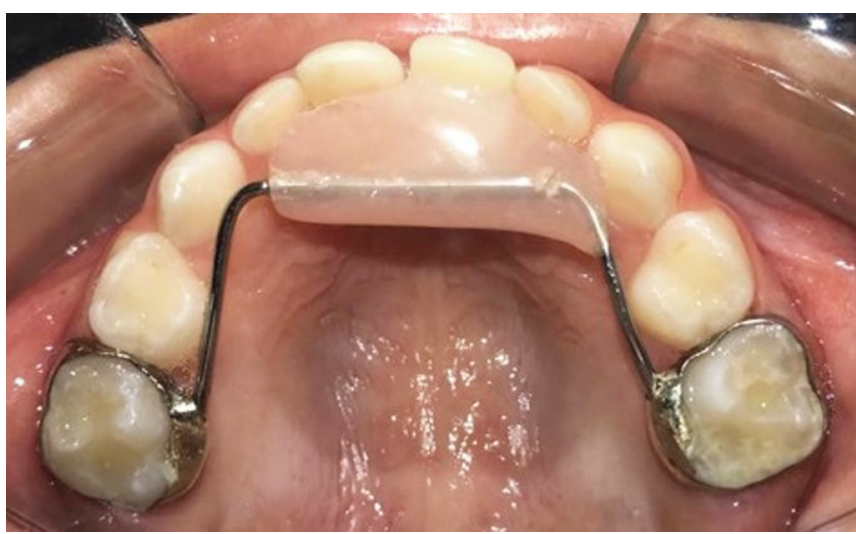

Fig. 3: Cementing the space maintainer after testing and making the necessary adjustments

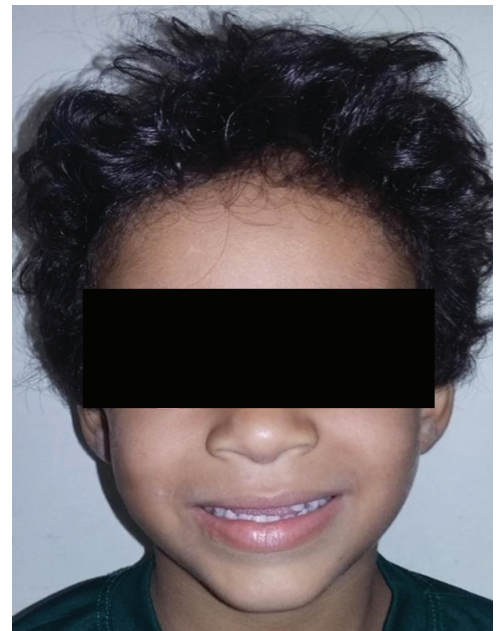

Fig. 5: Initial clinical aspect of the patient showing symmetrical face and upper lip depression due to the absence of teeth in the region 


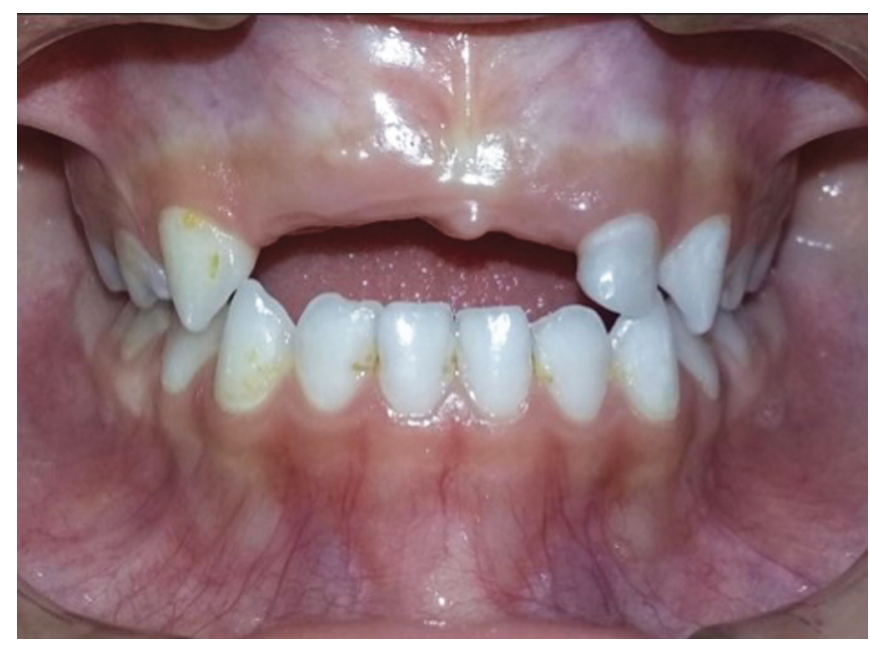

Fig. 6: Intraoral oral examination evidencing the absence of primary upper central incisors and left lateral incisor

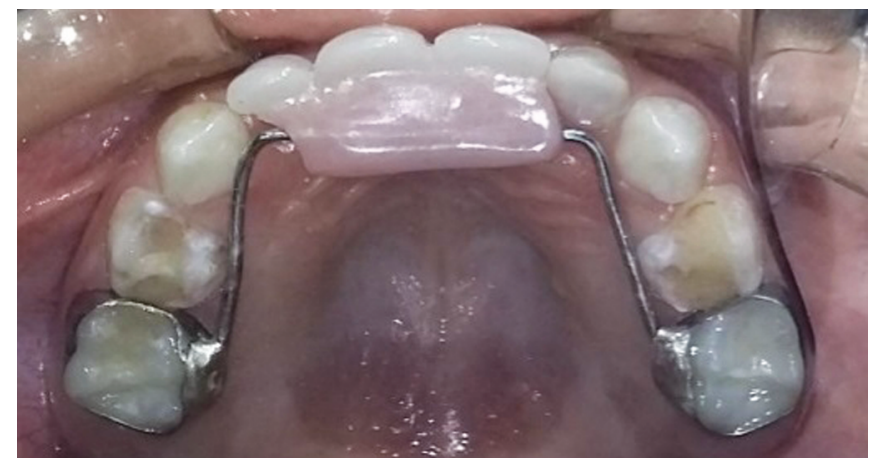

Fig. 8: Cementation of the space maintainer with modified glass ionomer cement

was only three years old and it is known that at this age the child is still learning to pronounce certain phonemes and the presence of anterior teeth is important for this learning to take place properly. ${ }^{7}$

In the rehabilitation of children, the device used should devolve function and esthetics, but should also respect maxillary growth. ${ }^{4,8}$ For this reason, removable prostheses have traditionally been indicated in these cases. However, the use of removable devices requires greater cooperation of the children ${ }^{5}$ and can cause discomfort, adapting difficulties or even loss of the space maintainer or non-compliance with the instructions for use. ${ }^{9}$ In fact, the use of removable devices for children is not recommended due to the lack of patient cooperation. ${ }^{10}$ Thus, an alternative for the treatment of these patients is presented.

In both cases, we chose the use of esthetic functional fixedspace maintainers with tube-bar system, initially described by Denari et al. in 1995 and subsequently modified. ${ }^{8}$ The maintainer has a socket with tubular male-female system, so that the system allows the slide of the bar inside the tube as the transverse growth of the maxilla occurs. A low-cost, minimally invasive, and wellperforming alternative measure for prosthetic rehabilitation for the early loss of anterior primary teeth is set up. ${ }^{8}$

Mainly in the rehabilitation of anterior teeth losses, the maintainers positively influence the behavior of the child, as well as prevent functional alterations. ${ }^{4}$ In both cases, patients and

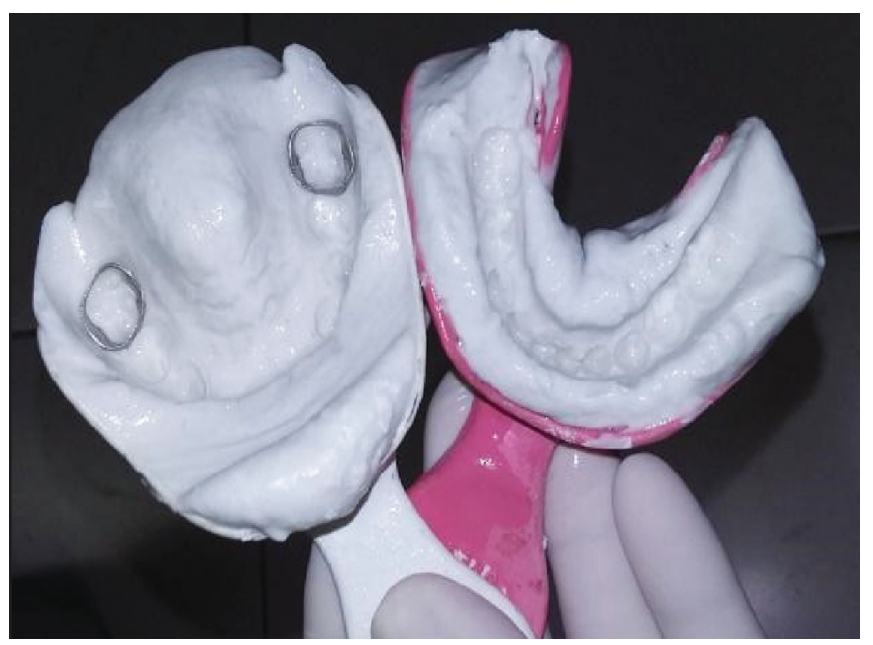

Fig. 7: Upper alginate impression and band transfer

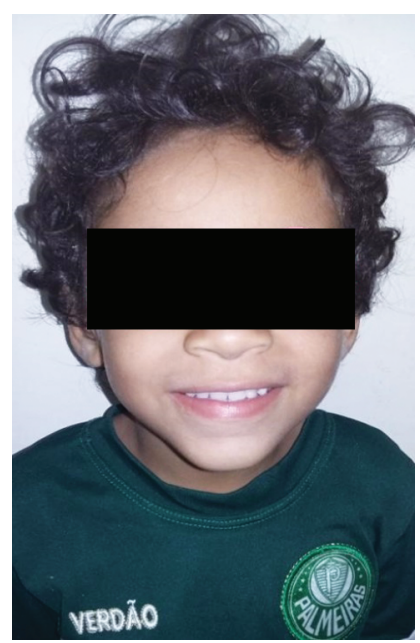

Fig. 9: Final aspect of the patient after cementing the esthetic functional space maintainer

their caregivers were very satisfied with the rehabilitation and are attending adequately to the programmed returns.

\section{Conclusion}

The rehabilitation of early losses of anterior primary teeth by fixed esthetic functional space maintainers with tube-bar system proved to be a favorable treatment option regardless of the age of the patient or the number of missing teeth.

\section{Clinical Significance}

Early loss of anterior primary teeth may have a major impact on the pediatric patient and is still a challenge in clinical practice. This article presents an effective and inexpensive alternative to this clinical situation.

\section{References}

1. Khare V, Nayak PA, Khandelwal V, et al. Fixed functional space maintainer: novel aesthetic approach for missing maxillary primary anterior teeth. BMJ Case Rep 2013(jun03 1):1-4. DOI: 10.1136/bcr2013-009585. 
2. Monte-Santo AS, Viana SVC, Moreira KMS, et al. Prevalence of early loss of primary molar and its impact in schoolchildren's quality of life. Int J Paediatr Dent 2018;28(6):595-601. DOI: 10.1111/ipd.12416.

3. Ahamed SSS, Reddy VN, Krishnakumar R, et al. Prevalence of early loss of primary teeth in 5-10-year-old school children in Chidambaram town. Contemp Clin Dent India 2012;3(1):27-30. DOI: 10.4103/0976$237 X .94542$.

4. Das PK, Datta P, Bora A, et al. A simple modification of aesthetic fixed appliance for replacement of avulsed maxillary primary incisors. Int J Appl Dent Sci 2015;1(5):23-25.

5. Law CS. Management of premature primary tooth loss in the child patient. CDA J 2014;41(8):612-618.

6. Garcia-Godoy F, Garcia-Godoy F, Garcia-Godoy FM. Primary teeth traumatic injuries at a private pediatric dental center. Endod
Dent Traumatol 1987;3(3):126-129. DOI: 10.1111/j.1600-9657.1987. tb00613.x.

7. Kalia G, Tandon S, Bhupali NR, et al. Speech evaluation in children with missing anterior teeth and after prosthetic rehabilitation with fixed functional space maintainer. J Indian Soc Pedod Prev Dent 2018;36(4):391-395. DOI: 10.4103/JISPPD.JISPPD_ 221_18.

8. Sousa JM, de, Jordão MC, Provenzano MGA, et al. The use of a modified fixed partial denture in childhood: clinical case reporting. Odontol Clín-Cient, Recife 2012;11(3):253-257.

9. Dominguez A, Aznar T. Removable prostheses for preschool children: report of two cases. Quintessence Int 2004;35(5):397-400.

10. Simon $\mathrm{T}$, Nwabueze $\mathrm{l}$, Oueis $\mathrm{H}$, et al. Space maintenance in the primary and mixed dentitions. 2012;94(1):38-40. 